\title{
Uma experiência local de patrimônio cultural e educação no Tocantins
}

\author{
Juliana Ricarte Ferraro* \\ Ariel Elias Nascimento**
}

\begin{abstract}
Resumo
Este artigo nasceu do projeto realizado na Universidade Federal do Tocantins (UFT), intitulado Patrimônio Cultural em sala de aula: novos olhares e saberes, realizado na cidade de Porto Nacional (TO), com objetivo de analisar a questão do Patrimônio Cultural e Educação Patrimonial nas escolas públicas de ensino básico. Partimos do conceito de patrimônio cultural, para pensarmos seu entrelaçamento com a educação e suas práticas em seus espaços formais e não formais. Esta experiência, descrita neste artigo, buscou contribuir com a valorização e reconhecimento da história local e desenvolver, através da educação patrimonial, novas formas de exploração do patrimônio cultural local.

Palavras-chave: Patrimônio Cultural; Educação; Porto Nacional; História Local.
\end{abstract}

\section{A local experience of cultural heritage and education in Tocantins}

\begin{abstract}
This article was born from a project carried out at the Federal University of Tocantins (UFT), titled Cultural Heritage in the classroom: new looks and knowledge, held in the city of Porto Nacional (TO), with the objective of analyzing the issue of cultural heritage and patrimonial education in public elementary schools. We start from the concept of cultural heritage, to think about its intertwining with education and its practices in its formal and non formal spaces. This experience, described in this article, sought to contribute to the appreciation and recognition of local history and to develop, through heritage education, new ways of exploring local cultural heritage.

Keywords: Cultural Heritage; Education; National Port; Local History.
\end{abstract}

\section{Patrimônio Cultural: alguns posicionamentos}

A palavra patrimônio pode assumir sentidos diversos e, originalmente, esteve relacionada à herança familiar. No século XVIII, na França, o poder público começou a tomar as primeiras medidas de proteção aos monumentos de valor para a história da nação e o uso da palavra estendeu-se para os bens protegidos por lei e pela ação de órgãos especialmente constituídos, nomeando o conjunto de bens culturais de uma nação e ou de um povo.

$\mathrm{O}$ primeiro conceito de patrimônio apresentado pelo Serviço do Patrimônio Histórico e Artístico Nacional - SPHAN, fundado em 1937, foi o seguinte: "Conjunto de bens móveis e imóveis existentes no país e cuja conservação seja de interesse público, quer por sua vinculação a fatos memoráveis na história do Brasil, quer por excepcional valor arqueológico ou etimológico, bibliográfico ou artístico".

Segundo Choay (2006, p.11), a palavra patrimônio, na sua origem, está ligada às estruturas familiares, econômicas e jurídicas de uma sociedade estável, enraizada no espaço e no tempo, tendo sido requalificada por diversos adjetivos (genético,

\footnotetext{
* Endereço Eletrônico: juferraro@uft.edu.br

** Endereço Eletrônico: ariel@uft.edu.br
}

natural, histórico) que fizeram dela um conceito nômade.

A expressão patrimônio histórico designa todo bem destinado ao usufruto de uma comunidade e que se ampliou a dimensões planetárias, constituindo-se de uma diversidade de objetos que se congregam a seu passado comum: obras e obrasprimas das belas-artes e das artes aplicadas, trabalhos e produtos de todos os saberes dos seres humanos. Patrimônio Histórico remete a uma instituição e a uma mentalidade (CHOAY, 2006, p.11).

No Brasil, o conceito de patrimônio histórico está previsto no art. 216 da Constituição da República Federativa do Brasil (BRASIL, 1988), sendo a sua proteção obrigação do poder público (art. 216, § 1º, BRASIL, 1988) e direito do povo.

Art. 216. Constituem patrimônio cultural brasileiro os bens de natureza material e imaterial, tomados individualmente ou em conjunto, portadores de referência à identidade, à ação, à memória dos diferentes grupos formadores da sociedade brasileira, nos quais se incluem:

I - as formas de expressão; 
II - os modos de criar, fazer e viver;

III - as criações científicas, artísticas e tecnológicas;

IV - as obras, objetos, documentos, edificações e demais espaços destinados às manifestações artístico-culturais;

$\mathrm{V}$ - os conjuntos urbanos e sítios de valor histórico, paisagístico, artístico, arqueológico, paleontológico, ecológico e científico.

$\S 1^{\circ}$. O Poder Público, com a colaboração da comunidade, promoverá e protegerá o patrimônio cultural brasileiro, por meio de inventários, registros, vigilância, tombamento e desapropriação, e de outras formas de acautelamento e preservação.

$\S 2^{\circ}$. Cabem à administração pública, na forma da lei, a gestão da documentação governamental e as providências para franquear sua consulta a quantos dela necessitem.

$\S 3^{\circ}$. A lei estabelecerá incentivos para a produção e o conhecimento de bens e valores culturais.

$\S 4^{\circ}$. Os danos e ameaças ao patrimônio cultural serão punidos, na forma da lei.

$\S 5^{\circ}$. Ficam tombados todos os documentos e os sítios detentores de reminiscências históricas dos antigos quilombos.

$\S 6^{\circ}$. É facultado aos Estados e ao Distrito Federal vincular a fundo estadual de fomento à cultura até cinco décimos por cento de sua receita tributária líquida, para o financiamento de programas e projetos culturais, vedada a aplicação desses recursos no pagamento de:

I - despesas com pessoal e encargos sociais;

II - serviço da dívida;

III - qualquer outra despesa corrente não vinculada diretamente aos investimentos ou ações apoiados.

No exercício de seus direitos, qualquer cidadão pode, por meio de ação popular (art. $5^{\circ}$, LXXIII, BRASIL, 1988), anular qualquer ato lesivo ao patrimônio histórico-cultural.

Art. $5^{\circ}$. - LXXIII - qualquer cidadão é parte legítima para propor ação popular que vise a anular ato lesivo ao patrimônio público ou de entidade de que o Estado participe, à moralidade administrativa, ao meio ambiente e ao patrimônio histórico e cultural, ficando o autor, salvo comprovada má-fé, isento de custas judiciais e do ônus da sucumbência.

O International Council on Monuments and Sites - ICOMOS (Conselho Internacional de Monumentos e Sítios), uma organização civil internacional ligada à UNESCO, apresenta em seus documentos os conceitos de patrimônio cultural, natural e imaterial, a saber:

-Patrimônio cultural:

- os monumentos: obras arquitetônicas, esculturas ou pinturas monumentais, objetos ou estruturas arqueológicas, inscrições, grutas e conjuntos de valor universal excepcional do ponto de vista da história, da arte ou da ciência;

- os conjuntos: grupos de construções isoladas ou reunidas, que, por sua arquitetura, unidade ou integração à paisagem, têm um valor universal excepcional do ponto de vista da história, da arte ou da ciência;

- os sítios: obras do homem ou obras conjugadas do homem e da natureza assim como áreas, incluindo os sítios arqueológicos, de valor universal excepcional do ponto de vista histórico, estético, etnológico ou antropológico (UNESCO, 1972).

-Patrimônio natural:

- os monumentos naturais constituídos por formações físicas e biológicas ou por conjuntos de formações de valor universal excepcional do ponto de vista estético ou científico;

- as formações geológicas e fisiográficas e as zonas estritamente delimitadas que constituam habitat de espécies animais e vegetais ameaçadas de valor universal excepcional do ponto de vista estético ou científico;

- os sítios naturais ou as áreas naturais estritamente delimitadas detentoras de valor universal excepcional do ponto de vista da ciência, da conservação ou da beleza natura (UNESCO, 1972).

\section{-Patrimônio imaterial:}

as práticas, representações, expressões, conhecimentos e técnicas - junto com os instrumentos, objetos, artefatos e lugares culturais que lhes são associados - que as comunidades, os grupos e, em alguns casos, os indivíduos reconhecem como parte integrante de seu patrimônio cultural (UNESCO, 2006).

O Instituto do Patrimônio Histórico e Artístico Nacional - IPHAN, um dos representantes do ICOMOS no Brasil, assim apresenta seus conceitos para patrimônio material e imaterial.

-Patrimônio material: 
O patrimônio material protegido pelo Iphan, com base em legislações específicas, é composto por um conjunto de bens culturais classificados segundo sua natureza nos quatro Livros do Tombo: arqueológico, paisagístico e etnográfico; histórico; belas artes; e das artes aplicadas. Eles estão divididos em bens imóveis como os núcleos urbanos, sítios arqueológicos e paisagísticos e bens individuais; e móveis como coleções arqueológicas, acervos museológicos, documentais, bibliográficos, arquivísticos, videográficos, fotográficos e cinematográficos.

-Patrimônio imaterial:

O Patrimônio Imaterial é transmitido de geração em geração e constantemente recriado pelas comunidades e grupos em função de seu ambiente, de sua interação com a natureza e de sua história, gerando um sentimento de identidade e continuidade, contribuindo assim para promover o respeito à diversidade cultural $\mathrm{e}$ à criatividade humana.

\section{Patrimônio e educação nos dias atuais}

Vivemos atualmente em uma sociedade avançada tecnologicamente, onde a facilidade de comunicação, o deslocamento de pessoas e a integração econômica, política e cultural são fatos comuns em nossas vidas. Nosso ambiente cotidiano está cada vez mais padronizado.

Nesse contexto, hoje, mais do que nunca, fica evidente que as diferenças e as diversidades culturais e naturais necessitam encontrar seus espaços de discussão, tanto na academia quanto na sociedade. $\mathrm{Na}$ era da globalização cresce o sentimento de unificação cultural, de padronização das técnicas, de homogeneização dos costumes, segundo identifica Fonseca (1997).

Contrapondo-se a esse movimento de padronização e pasteurização, passou-se, há algumas décadas, a se incentivar o processo de descoberta e valorização dos aspectos locais e regionais das sociedades, trazendo novos olhares para temáticas como memória, cultura e patrimônio. Essas, por sua vez, reforçaram-se como representações da nossa identidade e expressão cultural e histórica, sendo o patrimônio vinculado à valorização e preservação dos nossos referenciais identitários, que simbolizam a diferença e a diversidade da comunidade diante dos parâmetros globais.

Surge, dessa forma, a preocupação com o patrimônio nacional e mundial, seja natural ou cultural, que faz com que cada sociedade possa melhor conhecer a si mesma, assim como as relações que ao longo dos anos seus antepassados mantiveram com o meio do qual hoje faz parte e no qual exerce suas formas de subsistência, constituindo-se como fonte de aceitação do diferente, na compreensão cultural de outros povos. Desse modo, esse patrimônio, além de essencial para a coletividade como 'lugar' de memória, tornase um recurso importante no desenvolvimento da história local e regional (PESAVENTO, 1999).

A revitalização e a preservação significam um avanço da nossa sociedade, no sentido de retomar valores que há muito estavam fora do debate. A retomada das discussões sobre preservação, conservação e restauração do patrimônio e, essencialmente, a preocupação com espaços e manifestações que permitem o olhar, a convivência, o conhecimento e a interação com valores, histórias, símbolos e manifestações, pode trazer à sociedade uma cultura mais humana e mais próxima do meio ambiente em que vivemos, partindo de uma tomada de consciência geral, seguida de uma ação que lhe seja ideal (CHOAY, 2006).

Segundo CHOAY (2006, p. 369), a questão atual acerca da herança patrimonial trata de mostrar como os fatores que caracterizam a desterritorialização tendem a eliminar as riquezas patrimoniais que estão em jogo durante a longa duração do processo de antropização (paisagens rurais e urbanas como atividades e práticas sociais) e, ao mesmo tempo, fazer emergir um novo tipo de pobreza específica do fim do século XX. Não é mais questão nem de ecologia, nem de conservação patrimonial e nem de procurar um equilíbrio entre o global e o local. O desenvolvimento local e a reterritorialização devem ser considerados como uma alternativa estratégica ao desenvolvimento global.

Em alguns documentos institucionais da UFT (2003, 2003a, 2006, 2011), assim como em diversos projetos governamentais, percebemos que esses voltam sua atenção à importância da preservação do patrimônio cultural e os seus aspectos que, muitas vezes, encontravam-se (ou ainda encontram-se) esquecidos e relegados nas discussões das políticas públicas dos governos.

A atenção para o patrimônio cultural também se reflete nos textos dos Parâmetros Curriculares Nacionais (1997), que têm como um dos objetivos do ensino fundamental: 
[...] que os alunos sejam capazes de: conhecer e valorizar a pluralidade do patrimônio sociocultural brasileiro, bem como os aspectos socioculturais de outros povos e nações, posicionando-se contra qualquer discriminação baseada em diferenças culturais, de classe social, de crenças, de sexo, de etnia ou outras características individuais e sociais (PCN, 1997, p. 2).

Apesar de todo suporte teórico e institucional para que os patrimônios culturais fossem estudados, divulgados e ampliados na construção conjunta das identidades, reconhecendose seu pertencimento a elas, não se vislumbrava nenhum projeto de amplitude coletiva e de abrangência entre os saberes locais e acadêmicos.

No âmbito educacional, embora o patrimônio cultural seja mencionado em alguns documentos, nada, ou quase nada, acontece real e concretamente. As teorias encontram-se inteiramente desvinculadas da prática e as ações e relações entre sociedade e academia não se mantém ou não se realizam.

Desde final do século XX, a UNESCO (1972, 2006) reforça a necessidade da educação, conscientização e fortalecimento do patrimônio cultural, bem como a importância da participação das comunidades, grupos e indivíduos nas ações e gestões junto ao mesmo, por meio de programas educativos, programas de capacitação e de disseminação de informações voltadas ao público, em especial aos jovens.

$\mathrm{O}$ viés da consolidação do patrimônio cultural de determinada comunidade e/ou grupo, como o objetivo de fortalecer suas capacidades de salvaguardá-lo, encontra-se atrelado à ação educacional, para assim proteger os espaços e lugares de memória, cuja existência se faz indispensável para a própria continuidade das materialidades e expressões das identidades ante o mundo globalizado.

\section{Uma experiência local}

A experiência local com a questão do patrimônio cultural e educação patrimonial nasceu a partir do projeto intitulado Patrimônio cultural em sala de aula: novos olhares e saberes ${ }^{l}$, que surgiu com a pretensão de planejar e efetivar ações educativas e comunitárias na valorização, defesa e utilização desse patrimônio, gerando interatividade com os diversos saberes (acadêmicos e escolares), demonstrando o poder da sociedade na transformação de seu patrimônio cultural em ferramenta de desenvolvimento da sua realidade.

As ações educativas estão focadas em uma escola pública de Porto Nacional -TO, entre os alunos de $6^{\circ}$ ao $9^{\circ}$ ano do ensino fundamental, atuando como multiplicadores os respectivos professores, com a perspectiva de que essas ações funcionem como foco de diálogo e construção conjunta com a sociedade de um processo de identificação, reconhecimento, valorização, proteção e promoção do patrimônio cultural.

O projeto Patrimônio cultural em sala de aula: novos olhares e saberes justifica-se pelo objetivo de que a preservação de cada documento do patrimônio cultural, aqui tomado em seu sentido mais amplo, pode, ao longo do tempo, manter viva a história de um grupo ou sociedade, proporcionando o seu reconhecimento e sua valorização, o (re) descobrimento de sua identidade cultural.

A pesquisa firmou-se com a realização e efetivação das ações, juntamente com professores e alunos das escolas públicas de Porto Nacional - TO, ampliando-se as discussões e diálogos sobre o patrimônio cultural e a identidade local, verificando-se qual o envolvimento das crianças e adolescentes com sua própria história e do seu entorno, continuando a ter os professores como potenciais multiplicadores dessa ação educativa.

Acreditando que a partir do conhecimento e reconhecimento do patrimônio cultural local a população seja motivada a preservar seus bens culturais como parte efetiva de sua própria identidade, procuramos investigar qual é a efetiva aplicabilidade da temática do patrimônio cultural em sala de aula e quais os desdobramentos dessa prática para a preservação e valorização do patrimônio cultural de Porto Nacional - TO, a partir de estudo com os estudantes envolvidos. É essa a questão apresentada como problema de pesquisa para o projeto.

A partir dessa problemática, outras indagações sobre o tema ocorreram: quais as implicações da real efetivação dos conteúdos de patrimônio cultural em sala de aula para a construção do cidadão atuante e transformador de sua realidade?; como a educação patrimonial inserida no contexto escolar pode ajudar a construir novos olhares e realidades de atuação para a preservação do patrimônio, em seu mais amplo sentido de história, identidade e memória local e regional?; e, mais importante, em que sentido essa ação de educação patrimonial pode contribuir para despertar uma consciência de preservar e respeitar o 
patrimônio histórico e cultural de Porto Nacional TO?

Acreditamos que essa pesquisa pode impactar mudanças em todos os seus participantes, alunos/professores, na percepção da sua realidade e identidade cultural, visto que o diálogo, como forma de melhor compreensão de nossos espaços, possibilita reconhecer os elementos, conteúdos e sensibilidades, permitindo uma espécie de apropriação dos bens culturais estudados.

O trabalho com as heranças culturais de sua região permite que o aluno aprenda a resguardar a memória da comunidade e se sinta parte dela e, dessa forma, passe a atuar como agente de sua história e de seu patrimônio, fortalecendo sua identidade cultural. O professor, como orientador e multiplicador das ações educativas, não pode ser estudado isoladamente, separado de seus alunos e da continuidade do trabalho iniciado nesse projeto.

A relevância da pesquisa está em contribuir para a valorização da história local por meio de sua apropriação pelos alunos, bem como, no âmbito acadêmico e social, desenvolver, por meio da educação patrimonial, novas formas de exploração do patrimônio cultural de Porto Nacional -TO e cidades da região.

Como aporte teórico, fundamentamos nossa pesquisa e ações nas autoras Maria de Lourdes Parreiras Horta (2000) e Evelina Grunberg (2007), que afirmam a importância da educação patrimonial para o fortalecimento e a valorização da memória cultural, construindo autonomia na qual o aluno possa valorizar e se apropriar do conhecimento histórico em um processo de descoberta.

A Educação Patrimonial consiste em provocar situações de aprendizado sobre o processo cultural e, a partir de suas manifestações, despertar no aluno o interesse em resolver questões significativas para sua própria vida, pessoal e coletiva. O patrimônio histórico e o meio ambiente em que está inserido oferecem oportunidades de provocar nos alunos sentimentos de surpresa e curiosidade, levandoos a querer conhecer mais sobre eles (HORTA, 2000).

A partir do conhecimento, o aluno se sente parte integrante de sua história e, assim, se reconhece como agente transformador de sua realidade, demonstrando o poder da coletividade e da individualidade na construção dos significados de sua pluralidade e identidade cultural, a partir da valorização e preservação do patrimônio cultural. É nesse sentido que se fundamentou esse projeto, fazendo com que o aluno desperte sua curiosidade, buscando informações e aprimorando o olhar e o saber sobre o patrimônio, estimulando-o a valorizar sua cultura local e seus bens culturais.

As ações promovidas pelo projeto buscam desenvolver a percepção e o espírito crítico, por meio de metodologia especifica de trabalho, propiciando experiências e contato direto com as manifestações culturais, sejam bens materiais (edifícios, praças, mercados, jardins, fotografias, documentos, esculturas, quadros, instrumentos de trabalho, etc.) ou bens imateriais (músicas, danças, festas religiosas, ou populares, comidas, rituais, hábitos e costumes, formas de fazer, saberes e dizeres populares etc.).

A pesquisa apresenta abordagem qualitativa do tipo pesquisa-ação, pois esta modalidade de investigação se caracteriza como processo em que o pesquisador tem contato direto com o pesquisado por meio de ações que possibilitam a análise e a intervenção.

Num primeiro momento, verificou-se a existência ou não de trabalhos realizados sobre o patrimônio cultural da cidade em sala de aula. Em seguida, foi realizado um diagnóstico junto aos alunos participantes, objetivando verificar se eles compreendem o que é patrimônio, o que é patrimônio de Porto Nacional e se reconhecem esse patrimônio como seu.

Assim, no ano de 2012, o levantamento prévio em algumas das escolas selecionadas foi realizado entre os diretores, coordenadores pedagógicos e de áreas, professores e alunos. Para esse levantamento, foram apresentadas questões como:

Existem trabalhos sendo realizados (projetos, oficinas) sobre patrimônio cultural da cidade na escola ou em sala de aula com o professor de história? Acontece onde? Quando? Qual o público atingido? Quais os anos? O museu é utilizado como recurso de ensino? Como? Qual projeto? Qual o retorno que há destes alunos nas atividades realizadas? Eles compreendem o que é patrimônio cultural? Reconhecem o patrimônio da cidade? Se sentem pertencentes e se reconhecem nos patrimônios da cidade? (perguntas para $\mathrm{o}$ professor $\mathrm{e}$ coordenação/direção).

Essa etapa junto aos professores, diretores e coordenadores trouxe resultados alarmantes, pois não trabalhavam a temática de patrimônio cultural 
com os alunos, nem mesmo nas aulas de História; apenas uma das cinco escolas e apenas um professor, entre os doze consultados, havia feito uma visita ao museu da cidade, e isso há mais de cinco anos, com alunos do ensino fundamental.

Para os alunos, as questões apresentadas foram:

Existem trabalhos sendo realizados (projetos, oficinas) sobre patrimônio cultural da cidade na escola ou em sala de aula com o professor de história? Você já visitou o Museu da cidade? O que é patrimônio cultural? O que é o patrimônio cultural da cidade? Quais são estes patrimônios? $\mathrm{E}$ para você estes são importantes? O que e quais seriam os patrimônios da cidade? Você sabia que o centro histórico de Porto Nacional foi tombado pelo governo (IPHAN) ${ }^{2}$ ?

Quanto aos alunos, em sua maioria, sabiam falar, sem grandes rebuscamentos e teorias, o que entendiam como patrimônio cultural, apesar de nunca terem tido atividades e/ou ações voltadas ao tema. De todos os alunos que participaram da pesquisa, nenhum havia visitado o museu e nem mesmo sabiam de sua existência, assim como não sabiam dizer quais eram os patrimônios da cidade e que seu centro histórico havia sido tombado pelo IPHAN em 2008.

Depois de verificado o conhecimento prévio dos alunos e das escolas ficou bastante clara a importância do prosseguimento da pesquisa e do foco nas ações coletivas sobre Patrimônio Cultural. Para o ano de 2013, o foco será as ações de educação patrimonial a serem desenvolvidas para o êxito do trabalho como um todo, não desconhecendo que, pela sua abrangência, o trabalho poderá se estender além do prazo previsto.

As ações estarão pautadas por uma metodologia de educação patrimonial que sistematiza de forma coesa os objetivos do trabalho que se pretende desenvolver. A metodologia escolhida é a descrita pela pesquisadora Evelina Grunberg (2007), sendo apresentada em quatro etapas:

\section{Observação}

Nesta etapa, usamos exercícios de percepção sensorial (visão, tato, olfato, paladar e audição) por meio de perguntas, experimentações, provas, medições, jogos de adivinhação e descoberta (detetive), etc., de forma que se explore, ao máximo, o bem cultural ou tema observado.

2. Registro
Com desenhos, descrições verbais ou escritas, gráficos, fotografias, maquetes, mapas, busca-se fixar o conhecimento percebido, aprofundando a observação e o pensamento lógico e intuitivo.

3. Exploração

Análise do bem cultural com discussões, questionamentos, avaliações, pesquisas em outros lugares (como bibliotecas, arquivos, cartórios, jornais, revistas, entrevistas com familiares e pessoas da comunidade), desenvolvendo as capacidades de análise e espírito crítico, interpretando as evidências e os significados.

4. $\quad$ Apropriação

Recriação do bem cultural, através de releitura, dramatização, interpretação em diferentes meios de expressão (pintura, escultura, teatro, dança, música, fotografia, poesia, textos, filmes, vídeos, etc.), provocando, nos participantes, uma atuação criativa e valorizando assim o bem trabalhado.

Os resultados da aplicação dessa metodologia desenvolvem atividades que levam os participantes à reflexão, descoberta e atitude favorável a respeito da importância e valorização do patrimônio cultural. Para avaliar os resultados utilizaremos a metodologia de feedback a cada ação promovida, com diálogos entre os participantes (gerenciais e ouvintes) de todas as áreas envolvidas como história, arqueologia, educação, geografia e biologia, caracterizando uma ação interdisciplinar.

Pelas ações de educação patrimonial, no sentido de construir e dividir novos conhecimentos, e da investigação, os envolvidos na ação conhecem e entendem melhor seu entorno para assim se tornarem cidadãos transformadores da realidade que os cerca, exercendo seus direitos e suas cidadanias por meio de planos de preservação de seus patrimônios culturais e de sua identidade cultural.

Sendo Porto Nacional uma cidade tombada pelo IPHAN, desde 27 de novembro de 2008, acreditamos que as ações de educação patrimonial podem contribuir para despertar a consciência de preservar e respeitar seu patrimônio cultural, além de corroborar a indissociabilidade entre pesquisa, ensino e extensão, por meio do fortalecimento da preservação e da valorização do patrimônio da cidade, ao mesmo tempo em que pretendem contribuir com a comunidade científica na elaboração de novas formas de pesquisas para se trabalhar a educação patrimonial e conjunto com a sociedade, fortalecendo seus laços e seus pertencimentos. É a partir do conhecimento e reconhecimento do patrimônio cultural local que a 
população se reconhece como parte ativa de sua/nossas histórias, e é motivada a preservar seus bens culturais como parte efetiva de sua própria identidade e sua memória.

\section{Notas}

1 Este trabalho é fruto de uma pesquisa desenvolvida sob minha coordenação na UFT Universidade Federal do Tocantins, no Campus de Porto Nacional, iniciada no ano de 2012, e ainda em execução.

2 "O Conselho Consultivo do Patrimônio Histórico e Artístico Nacional do Iphan se reuniu no Rio de Janeiro, no dia 27 de novembro, para aprovar o tombamento do Centro Histórico de Porto Nacional (TO) e o registro do modo de fazer a Renda Irlandesa produzida pelas rendeiras de Divina Pastora (SE). Estes bens têm agora o título de Patrimônio Cultural do Brasil. A proposta de tombamento de Porto Nacional se insere nas estratégias atuais de preservação do Iphan que procuram evidenciar contextos históricos associados a porções do território, de modo a favorecer a compreensão dos fenômenos responsáveis pela ocupação e urbanização do Brasil. A área tombada (que inclui o seu entorno) abrange parte da zona central da cidade e compreende o sítio natural, a malha urbana e as arquiteturas nela implantadas desde a fundação do município até a década de 1960 . No trecho estão localizados, além das edificações vernaculares, os edifícios mais singulares do Centro Histórico, como a Catedral, o Seminário, a Cúria e a Casa de Câmara e Cadeia. O local ainda apresenta remanescentes da maior parte do acervo arquitetônico representativo do período do Ciclo do Ouro (metade do século 18) até meados do século 20. O Centro Histórico de Porto Nacional foi inscrito no Livro do Tombo Histórico." Disponível em:

<http://portal.iphan.gov.br/portal/montarDetalheCo nteudo.do?id $=14189 \&$ sigla $=$ Noticia $\&$ retorno $=$ det alheNoticia>. Acessado em: 31. Maio. 2013.

\section{Referências}

BRASIL. Constituição da República Federativa do Brasil. Brasília, DF: Senado, 1988.
BRASIL. Secretaria de Educação Fundamental. Parâmetros curriculares nacionais: pluralidade cultural, orientação sexual. Brasília: MEC/SEF, 1997.

CHOAY, F. A alegoria do patrimônio. São Paulo: Estação Liberdade: UNESP, 2006.

FONSECA, M. C. L. O patrimônio em processo: trajetória da política federal de preservação no Brasil, Rio de Janeiro: UFRJ/IPHAN, 1997.

UFT/GOVERNO FEDERAL. Universidade Federal do Tocantins. Regimento Geral da Fundação Universidade Federal do Tocantins - UFT. Palmas, 2003.

UFT/GOVERNO FEDERAL. Universidade Federal do Tocantins. Estatuto da Fundação Universidade Federal do Tocantins - UFT. Palmas, 2003a.

UFT/GOVERNO FEDERAL. Universidade Federal do Tocantins. Planejamento Estratégico (2006 2010): por uma universidade consolidada democrática, inserida na Amazônia. Palmas, 2006.

UFT/GOVERNO FEDERAL. Universidade Federal do Tocantins. Plano de Desenvolvimento Institucional (PDI) da Universidade Federal do Tocantins 2011-2015. Palmas, 2011.

GRUNBERG, E. Manual de atividades práticas de educação patrimonial. Brasília, DF: IPHAN, 2007.

HORTA, M. L. P. Fundamentos da educação patrimonial. Ciências \& Letras, Porto Alegre, FAPA, n. 27, jan/jul. 2000.

HORTA, M. L. P.; GRUNBERG, E.; MONTEIRO, A. Q. Guia básico de educação patrimonial. Brasília: IPHAN/ Museu Imperial, 2000.

PESAVENTO, S. J. O imaginário da cidade. Visões literárias do urbano. Porto Alegre: UFRGS, 1999.

UNESCO. Convenção para a proteção do patrimônio mundial, cultural e natural. Paris, 1972.

UNESCO. Convenção para a salvaguarda do patrimônio cultural imaterial. Brasília, 2006. 


\section{Sobre os autores}

Juliana Ricarte Ferraro é Professora Adjunto I da Universidade Federal do Tocantins, no curso de História. Possui doutorado em Educação pela Universidade de São Paulo/USP; Especialização em Restauro e Conservação de Documentação Gráfica pela Faculdade Senai de São Paulo; Mestrado e graduação em História pela Universidade Estadual de Campinas.

Ariel Elias Nascimento é Mestre em História pela Universidade Estadual de Campinas. Possui Especialização em História, Sociedade e Cultura pela Pontifícia Universidade Católica de São Paulo; Graduação em História pela Pontifícia Universidade Católica de Campinas.

Recebido em dezembro de 2016.

Aprovado em março de 2017. 